\title{
Investigation on Microwelding of Microchip by Laser without Solder
}

\author{
Jianwen Yuan, Jimin Chen*, Furong Liu and Chao Huang \\ Institute of Laser Engineering, Beijing University of Technology, Beijing, 100124, China
}

Laser reflow soldering is of great importance in surface mount technology for the advantages of non-contact, local fast heating and cooling. Compared with $\mathrm{Sn}-\mathrm{Pb}$ solder, lead-free solder has higher melting point and poorer wetability and becomes deterioration easily in the air. This undoubtedly brings new challenges for reflow soldering. In this paper fiber laser with high energy density was used to weld three microchips (QFP-44, SSOP-48, SOP-14) without solder at the parameter of $20 \mathrm{kHz}$ repetition rate, $18 \mathrm{~W}$ in average power and $20 \mathrm{~mm} / \mathrm{s}$ of the speed. The properties of micro-joints of laser welding without solder were analyzed including electric property test, X-ray nondestructive test, $45^{\circ}$ pull test for tensile strength as well as SEM and EDS for fracture surface analyses. It shows the properties can meet the requirement of welding joint for microchips. [doi:10.2320/matertrans.MD201211]

(Received November 30, 2012; Accepted April 5, 2013; Published May 25, 2013)

Keywords: microwelding microchip, laser welding, without solder, micro-joints quality

\section{Introduction}

Laser soldering was first applied to microelectronics assembling using a $\mathrm{CO}_{2}$ laser in 1974. ${ }^{1)}$ In 1976 the first commercial laser soldering equipment was put into use. ${ }^{2)}$ After that, researches ${ }^{3,4)}$ on laser soldering technique and the equipment have developed rapidly. Compared with traditional reflow soldering such as infrared reflow soldering, hot air reflow soldering, gas phase or hot plate reflow soldering, which put the entire device into the welding stove in a whole heating, laser soldering is of the advantages of local noncontact fast heating and cooling as well as the features of flexibility. In addition, laser soldering owns the potential superiority of assembling high reliability thermo-sensitive element and static electric-sensitive device. It has been applied to surface mounted devices (SMD) [resistor, capacitor, small size package] and quad flat package (QFP) ${ }^{5)}$

Nowadays investigations ${ }^{6-8)}$ on laser reflow soldering mainly focus on lead-free reflow soldering. For example, NUAA has studied mechanical properties and microstructures of $\mathrm{Sn}-\mathrm{Ag}-\mathrm{Cu}$ and $\mathrm{Sn}-\mathrm{Cu}-\mathrm{Ni}-\mathrm{Ce}$ solder. However, with the size of electronic components decreasing, reflow soldering processing is easily influenced by solder printing result. In addition, the density of lead-free solder is lower than $\mathrm{Sn}-\mathrm{Pb}$ solder bringing more difficulties to screen printing. Moreover, lead-free solder has short life and is hard to store even in low temperature $\left(0-10^{\circ} \mathrm{C}\right)$.

It's necessary to develop a technique for laser welding electronic components without solder. Firstly it will remove solder and printing process, which can greatly lower the cost. Secondly ultra-fine lead soldering will get rid of the limits of printing technology. It can make the lead width less than $0.1 \mathrm{~mm}$ rather than generating bridge defect. Thirdly it will be more flexible to assemble chips at any position on the PCB. For example, the chip needs to be assembled at the marked position showed in Fig. 1. Laser direct welding without solder can weld the chip and PCB pad easily while the existing solder methods maybe much complicated due to considering how to avoid the influence of other components around it to make printing template and print solder. In this

*Corresponding author, E-mail: Jimin@bjut.edu.cn

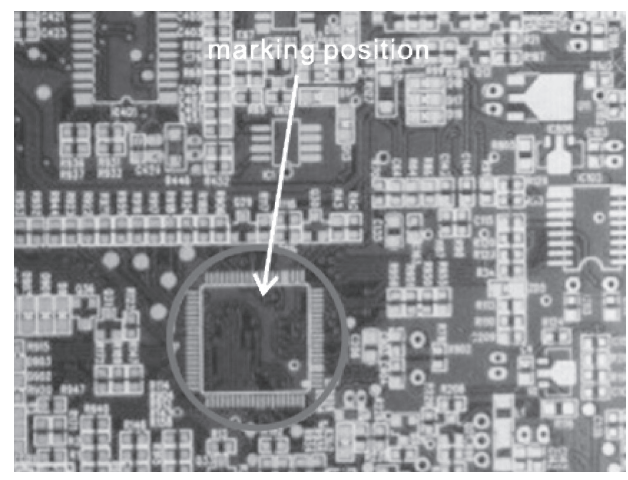

Fig. 1 The chip needs to be assembled separately.

study, three microchips welded by laser without solder was studied using a fiber laser. And the quality of the micro-joints realized by laser welding was assessed by electrical, mechanical tests and X-ray inspection. Moreover, the fracture surface was analyzed by SEM to determine the tensile failure mode.

\section{Experimental Procedure}

\subsection{Process}

The PCB and chips were cleaned by alcohol firstly to remove dirt and other. Then the rosin flux was applied on the pad before welding. A $20 \mathrm{~W}$ pulse fiber laser $(\lambda=1064 \mathrm{~nm})$ was used in the welding experiments. Figure 2 shows the laser beam was scanned across the workpiece using computer to control galvanometer mirrors and focusing with an $\mathrm{f}-\theta$ lens ( $\mathrm{f}=186 \mathrm{~mm}$, focus spot size $=50 \mu \mathrm{m})$.

The variables such as laser power $(10-20 \mathrm{~W})$, scan speed $(10-50 \mathrm{~mm} / \mathrm{s})$, repetition rate $(20-80 \mathrm{kHz})$, were changed to identify the optimized values of parameters for laser welding of the chip. Figure 3 shows the welded chips after cleaning under a parameter of $18 \mathrm{~W}, 20 \mathrm{~mm} / \mathrm{s}, 20 \mathrm{kHz}$. After cleaning the residual flux, the electric property of the LM324 (SOP14) was tested by a simple circuit. The quality of the microjoints was determined by X-ray inspection and by $45^{\circ}$ pull test. The fracture surface appearance was observed by scanning electron microscope (SEM) and the element was analyzed by energy diffraction spectrum (EDS). 


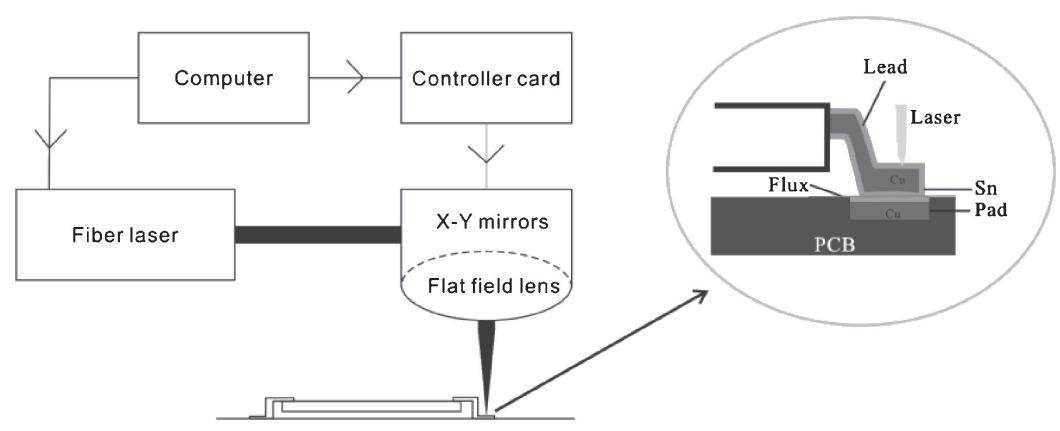

Fig. 2 Schematic of the arrangement used for laser welding.
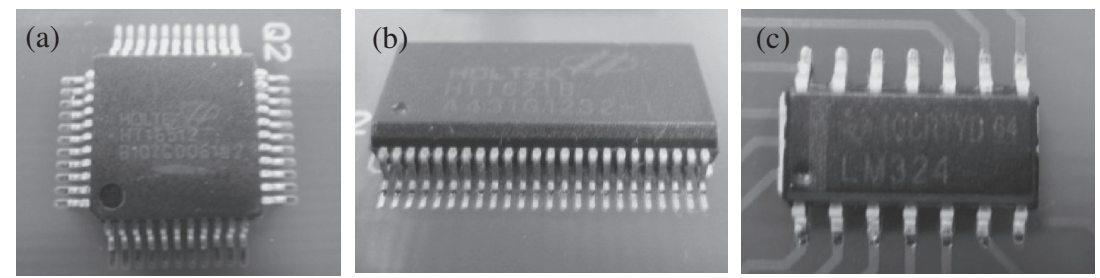

Fig. 3 The appearance of the chips after welding. (a) QFP. (b) SSOP. (c) SOP.

Table 1 Detailed parameters of the chips' leads.

\begin{tabular}{ccccccc}
\hline Package Type & Chip Type & Pin Count & $\begin{array}{c}\text { Lead } \\
\text { width/mm }\end{array}$ & $\begin{array}{c}\text { Lead } \\
\text { pitch/mm }\end{array}$ & $\begin{array}{c}\text { Lead } \\
\text { length/mm }\end{array}$ & $\begin{array}{c}\text { Lead } \\
\text { thickness/mm }\end{array}$ \\
\hline SOP & LM324 & 14 & $0.36-0.61$ & 1.27 & $0.40-1.27$ & 0.20 \\
SSOP & HT1621 & 48 & $0.203-0.305$ & 0.635 & $0.635-0.889$ & 0.10 \\
QFP & HT16512 & 44 & 0.30 & 0.80 & $0.73-0.93$ & 0.20 \\
\hline
\end{tabular}
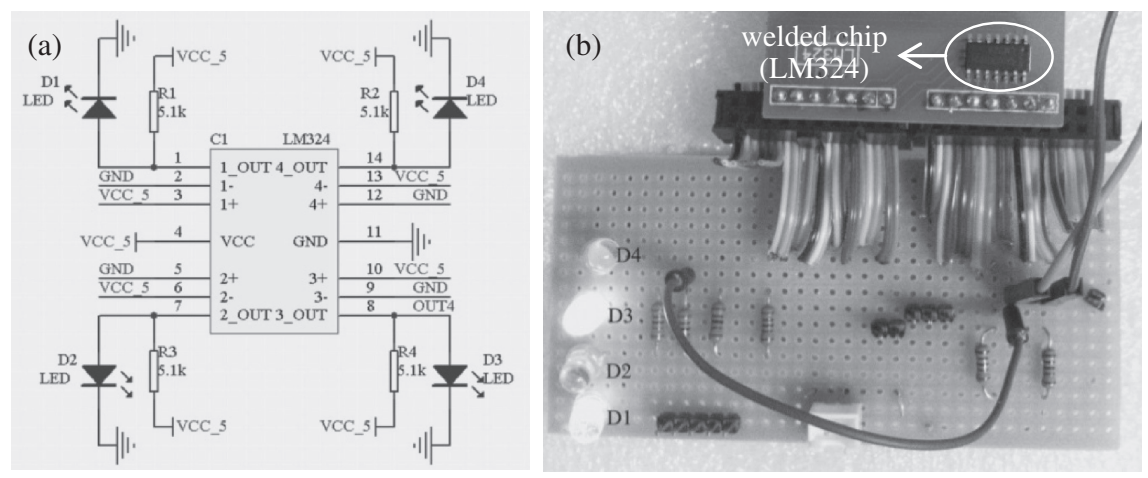

Fig. 4 The detection circuit. (a) Schematic diagram. (b) Practical circuit.

\subsection{Materials}

The test components used were a small outline package (SOP) chip with 14 leads, a shrink small outline package (SSOP) chip with 48 leads, and a QFP chip with 44 leads. Table 1 lists the detail parameters of the chips' leads. The printed circuit board (PCB) was made of FR4 material and pretinned copper $(\mathrm{Cu})$ tracks. The used flux was a white paste material, and its main ingredient is rosin. It is neutral (PH $=7 \pm 0.3)$.

\section{Results and Discussions}

\subsection{Electric property of LM324 test}

The test chip LM324 is a kind of low-cost, quad operational amplifier, which can also be used as comparator.
This chip has 14 leads. Figure 4(a) shows the schematic diagram of the detection circuit. C1 is the chip LM324 using as a comparator. Only when the output voltage is high-level, the LED connected with the output pin will be lighted up. If the chip LM324 works well after supplying voltage, D1 and D3 will go on while D2 and D4 will be in out. Figure 4(b) displays the practical detection circuit and on the power up state. Obviously the welded LM324 chip can work well. This proves that laser welding microchip without solder can achieve good connection between chip leads and PCB pads and the chip wasn't damaged by laser energy.

\subsection{X-ray nondestructive inspection}

The X-ray perspective view is able to display the thickness, shape of the solder joint and defects of the solder 

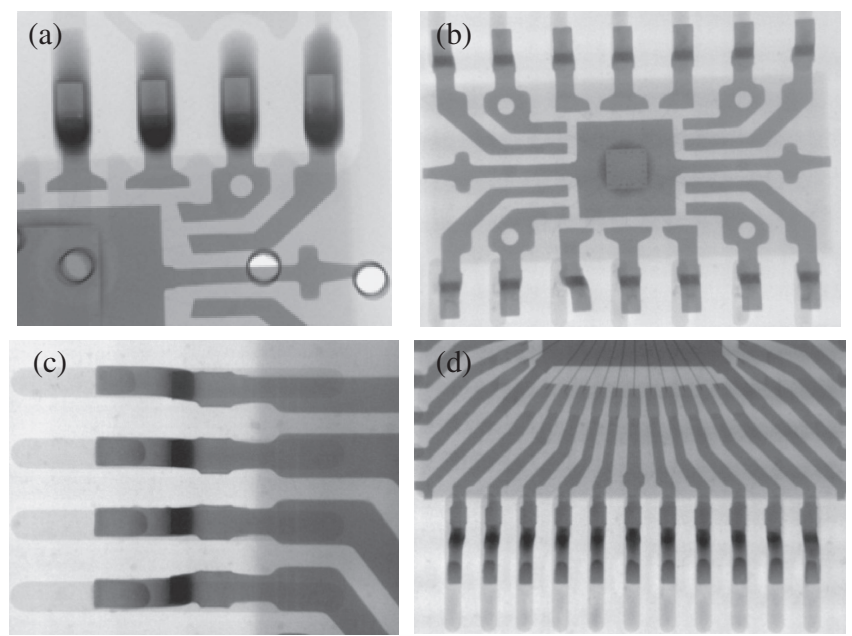

Fig. 5 X-ray images. (a) IR reflow soldering with $\mathrm{Sn}-\mathrm{Pb}$. (b) Original joints without welding. (c) SSOP-48 welded by laser without solder. (d) QFP-44 welded by laser without solder.

joints inside. Figure 5 shows the X-ray images of different welded joints. An X-ray image of the chip welded by IR reflow soldering with $\mathrm{Sn}-\mathrm{Pb}$ solder is presented in Fig. 5(a). It shows vivid gray level. The solder joints absorbed X-ray presenting a deep color and uniform in size, which indicates the solder joints are excellent and don't have any defects. Figure 5(b) displays an X-ray photo that is a SOP-14 device just put on the PCB before welding. It makes clear if the welding spots weren't formed the X-ray image doesn't have gray level change. Figures 5(c) and 5(d) display the welded SSOP-48 and QFP-44 chips by laser without solder. Compared with the two former pictures, it proved that the joints by laser welding without solder are achieved and don't have bubble or crack defects. However, it also shows there are some differences in size of the joints. This is due to the laser welded chip legs point by point scanning and input heat of each welding spot has some difference.

\subsection{Tensile strength test}

Japanese industrial standards (JIS) Z3198 about test methods for lead-free solders, part 6: methods for $45^{\circ}$ pull test of solder joints on QFP lead, was used to test the tensile strength of the micro-joints of all the chips welded by laser without solder. Figure 6 shows the schematic of $45^{\circ}$ pull test.

We randomly selected 12 welded joints to test at first. The results obtained are unsatisfactory showed in Fig. 7. Though the maximum pull strength have reached $3549 \mathrm{gf}$ $(35.49 \mathrm{~N})$, which is larger than the conventional reflow soldering's, the minimum pull strength was only $240 \mathrm{gf}$ $(2.4 \mathrm{~N})$ and most were less than $10 \mathrm{~N}$. The possible reasons of this large variation might be following.

(1) Lack of coplanarity of the leads: This means that not all the leads will be in contact with the pads when the device is placed on top of the PCB. Good contact is essential for laser soldering. This problem can be solved by applying a pressure force of $>1600 \mathrm{~g}^{9)}$ to the device causing the leads to be pressed against the solder pads and contacted well.

(2) Amount of flux used: The excessive flux spreads out along the pads. It will cause a lower temperature rising (a)

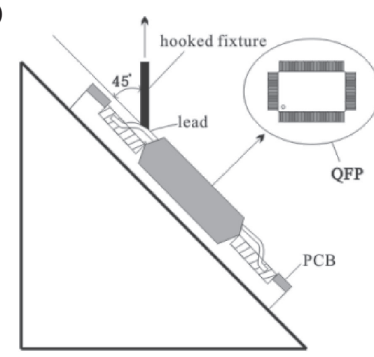

(b)

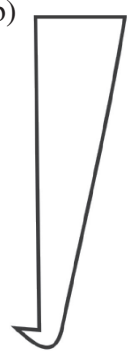

Fig. 6 Schematic of $45^{\circ}$ pull test. (a) Fixation method. (b) Hooked fixture.

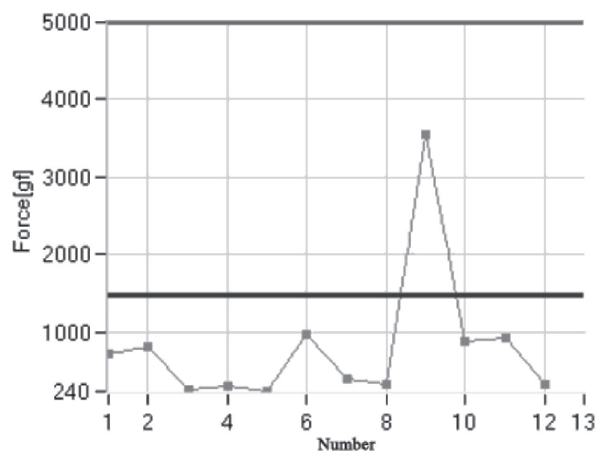

Fig. 7 Tensile force of random 12 micro-joints.

Table 2 Tensile strength of laser welding micro-joints without solder.

\begin{tabular}{ccrrrrrrrr}
\hline & 1 & \multicolumn{1}{c}{2} & \multicolumn{1}{c}{3} & \multicolumn{1}{c}{4} & \multicolumn{1}{c}{5} & \multicolumn{1}{c}{6} & $\bar{F} / \mathrm{gf}$ & $S / \mathrm{mm}^{2}$ & $R_{\mathrm{m}} / \mathrm{MPa}$ \\
\hline SOP-14 & 1298 & 1539 & 1800 & 1086 & 1124 & 943 & 1257 & 0.24 & 52.4 \\
SSOP-48 & 1164 & 975 & 1346 & 1171 & 1051 & 1293 & 1087 & 0.15 & 72.4 \\
QFP-44 & 1414 & 1189 & 1595 & 1498 & 1469 & 1020 & 1375 & 0.24 & 57.3 \\
\hline
\end{tabular}

during welding due to the withdrawal of heat required for evaporation. The evaporation of the flux during welding is also known to cause irregular heat transfer and to generate pores in the soldered joints. ${ }^{10)}$

(3) Inaccurate placement of the device: If the leads were misaligned with the pads, it will be in turn causing different leads to pads contact area and circuit board exposed to the laser beam. This can be avoided by using visual inspection system to replace human eyes.

(4) Different laser soldering parameters: Studies ${ }^{11,12)}$ have shown that the tensile strength of soldered joints is influenced remarkably by laser output power and soldering speed. Therefore only the optimum values of laser welding parameters will achieve strong tensile strength of the micro-joints. Through experiments, the laser welding parameter was optimized to be $18 \mathrm{~W}$, $20 \mathrm{~mm} / \mathrm{s}, 20 \mathrm{kHz}$.

Table 2 shows the measured tension value after improving the above issues as much as possible. Relevant article ${ }^{13)}$ has pointed out that generally the peel strength of $\mathrm{Cu}$ pad is $16 \mathrm{~N} / \mathrm{mm}^{2}$. If the QFP device's pin width is $d \mathrm{~mm}$, pin length is $T \mathrm{~mm}$, pad length is $l \mathrm{~mm}$, the $45^{\circ}$ pull strength can be calculated according to the empirical eq. (2).

$$
l=T+\mathrm{b} 1+\mathrm{b} 2(\mathrm{~b} 1=\mathrm{b} 2=0.3-0.5 \mathrm{~mm})
$$



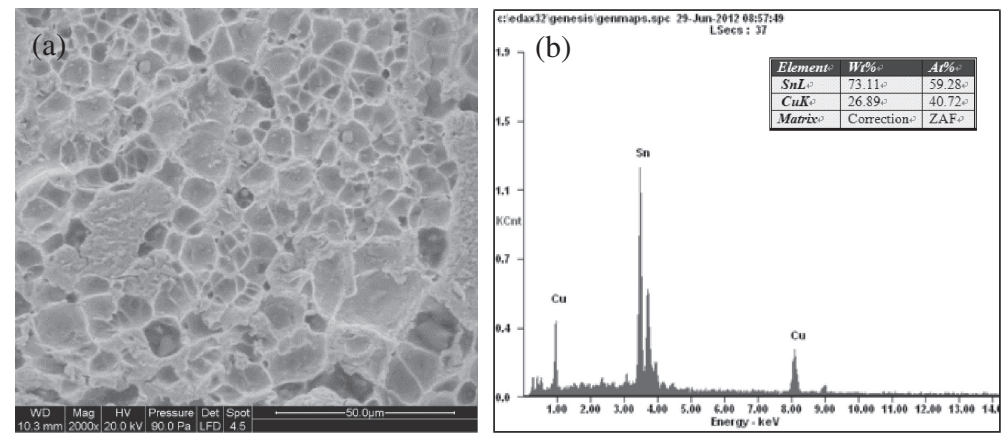

Fig. 8 Fracture microstructures of QFP micro-joints by laser welding without solder. (a) SEM micrographs. (b) EDX analysis graphics.

Table 3 The tensile strength of empirical calculation value for each chip.

\begin{tabular}{cclcr}
\hline Chips & $d / \mathrm{mm}$ & $T / \mathrm{mm}$ & $l / \mathrm{mm}$ & $F / \mathrm{gf}$ \\
\hline SOP-14 & 0.4 & 0.6 & 1.2 & 1086 \\
SSOP-48 & 0.6 & 0.762 & 1.6 & 938 \\
QFP-44 & 0.3 & 0.8 & 1.6 & 1108 \\
\hline
\end{tabular}

$$
F=1000 \times \frac{16 d l}{g \sin 45^{\circ}}(\mathrm{gf})
$$

Table 3 lists the force of calculated value according to formula 2. Compared Table 2 and Table 3, under the optimum values of laser welding parameters, all the $45^{\circ}$ pull strengths are larger than the empirical calculated value. That indicates the chip welded by laser without solder can meet the SMT process requirement in tensile strength. What's more, the tensile strengths of the test chips were larger than the tensile strength of $\mathrm{Sn}-\mathrm{Cu}$ eutectic solder $(23 \mathrm{Mpa}) .{ }^{14)}$ It shows the welding spots achieved metallurgical bonding.

\subsection{Fracture microstructures of micro-joints analysis}

Fracture mechanisms can usually be divided into ductile fracture and brittle fracture by the way of fracture. Ductile fracture refers to having obvious macroscopic plastic deformation before fracture. This kind of fracture has a slow tear process and plenty of fine dimples and microvoids on the fracture surface. Brittle fracture happens suddenly and has little plastic deformation before fracture. ${ }^{15}$ )

Figure 8 shows the micrograph of the fracture surface using SEM and chemical composition analysis using EDS techniques. It's known from Fig. 8(a) that the fracture surface was mainly ductile fracture because of existing lots of dimples. They indicate it has generated obvious plastic deformation before fracture. Figure 8 (b) reveals the chemical composition of the fracture surface is $\mathrm{Sn}$ and $\mathrm{Cu}$. It indicates the $\mathrm{Cu}$ was diffused in $\mathrm{Sn}$ when the $\mathrm{Sn}$ melted by laser energy and they formed intermetallic compound $\mathrm{Cu}_{6} \mathrm{Sn}_{5}$ after cooling. $\mathrm{Cu}_{6} \mathrm{Sn}_{5}$ does well to improving the tensile strength. ${ }^{16)}$

\section{Conclusion}

The SOP, SSOP, QFP devices have been welded to PCB pads by laser welding without solder and achieved good micro-joints. Through electric property of the LM324 device test it proved the welded joints can enforce good electric properties. Under the laser welding parameters of $18 \mathrm{~W}$, $20 \mathrm{~mm} / \mathrm{s}, 20 \mathrm{kHz}$, the tensile strength of SOP devices reached $52 \mathrm{MPa}$ (SSOP 72 MPa, QFP 57.3 MPa). It was equal to the tensile strength of IR reflow soldering with $\mathrm{Sn}-\mathrm{Pb}$ solder. The fracture type was ductile fracture observed by SEM. And it formed intermetallic compound $\mathrm{Cu}_{6} \mathrm{Sn}_{5}$ in the welding joints analyzed by EDS.

The laser welding without solder has great advantages for chip repairing on PCB as well as cutting the cost. However it needs further study on many respects such as reliability, cycle test, vibration and drop test. We will publish the test results in future.

\section{Acknowledgments}

This work was supported by Beijing Education Committee under grant No. KZ200910005006.

\section{REFERENCES}

1) C. F. Bohman: Soc. Manuf. Eng. 19 (1974) AD74-AD810.

2) T. Kujawa: Lasers Appl. 9 (1982) 93-94.

3) C. Lea: Microelectron. Int. 4 (1987) 36-42.

4) I. Fidan: J. Electron. Packag. 126 (2004) 173-176.

5) D. G. Whitehead and A. V. Polijanczuk: ASME Heat Transfer Div. 143 (1990) 47-56.

6) K. Nogita, J. Read and T. Nishimura: Mater. Trans. 46 (2005) 24192425.

7) Z. Han, S. Xue and J. Wang: Trans. China Weld. Inst. 28 (2007) 3336.

8) X. Zhang, S. Xue and Z. Han: Trans. China Weld. Inst. 29 (2008) 2226.

9) A. Flanagan, A. Conneely, T. J. Glynn and G. Lowe: J. Mater. Process. Technol. 56 (1996) 531-541.

10) R. J. K. Wassink: Soldering in Electronics, (Electrochemical Publications, Ayr, Scotland, 1984) pp. 318-322.

11) L. Yao, S. Xue and P. Wang: Trans. China Weld. Inst. 26 (2005) 90-92.

12) S. Xue, Huangxiang and Y. Wu: Trans. China Weld. Inst. 28 (2007) 21-24.

13) J. W. Shi, H. P. Yuan, H. L. Zhou and H. P. Wang: Electron. Process. Technol. 26 (2005) 259-263.

14) F. Guo: Lead-Free Soldering Technology and Application, (Science Press, Beijing, 2005) p. 87.

15) J. Sun, G.-G. Meng and Y.-S. Chen: Electron. Process. Technol. 32 (2011) 262-264.

16) W. Zhang: SMT Practical Guide, (Publishing House of Electronics Industry, Beijing, 2011) pp. 44-47. 